\title{
Cervical Myelopathy due to Tubercular Retropharyngeal Abscess
}

\author{
MD. ROBED AMI N, ${ }^{1}$ SHANTONU KUMER SAHA, ${ }^{2}$ HAFIZSARDAR, ${ }^{1}$ AHMEDUL KABIR, ${ }^{1}$ ANISUR RAHMAN HAWLADER, ${ }^{1}$ \\ MD FERDOUS ZAMAN, ${ }^{3}$ FAI ZUL ISLAM CHOWDHURY, ${ }^{4}$ MD. ABUL KASHEM KHANDAKER ${ }^{5}$
}

\begin{abstract}
Tuberculosis is the commonest infectious disease in developing country. A retropharyngeal abscess is an immediate life-threatening emergency, with potential for airway compromise and other catastrophic complications. We report the clinical, radiological and histological findings of symptomatic 16 years old girl with the features of cervical cord compression due to retropharyngeal abscess of tubercular origin. The patient improved after surgical management of abscess was done followed by anti-tuberculous drugs.
\end{abstract}

Keyword: Retropharyngeal abscess, extrapulmonary tuberculosis, compressive myelopathy

\section{Introduction}

Tuberculosis is the commonest infectious disease in developing country with variable clinical entity and presentation. One of the many presentations is tuberculosis of the spine, or Pott's disease. This clinical entity is rare, but it should be strongly suspected in a patient who presents with a destructive lesion of the vertebra and a retropharyngeal mass that extends across the midline. ${ }^{1}$ A retropharyngeal abscess is an infection in one of the deep spaces of the neck. An abscess in this location is an immediate lifethreatening emergency, with potential for airway compromise and other catastrophic complications. ${ }^{2}$ The retropharyngeal space is located immediately posterior to the nasopharynx, oropharynx, hypopharynx, larynx, and trachea. The visceral (ie, buccopharyngeal) fascia, which surrounds the pharynx, trachea, esophagus, and thyroid, forms the anterior border of the retropharyngeal space. ${ }^{3}$ Bounded posteriorly by the alar fascia, the retropharyngeal space is bounded laterally by the carotid sheaths and parapharyngeal spaces. It extends superiorly to the base of the skull and inferiorly to the mediastinum at the level of the tracheal bifurcation. Complications of retropharyngeal abscesses are secondary to mass effect, rupture of the abscess, or spread of infection. The most urgent complication involves the abscess expanding against the pharynx or trachea, causing airway compression. Rupture of the abscess can cause aspiration of pus, resulting in asphyxiation or pneumonia. The infection can spread, resulting in inflammation and destruction of adjacent tissues. Posterior spread of infection can result in osteomyelitis and erosion of the spinal column, causing vertebral subluxation and spinal cord injury ${ }^{2}$. The infection itself can evolve into necrotizing fasciitis, sepsis, and death.

We report the clinical, radiological and histological findings of symptomatic 16 years old girl with the features of cervical cord compression due to retropharyngeal abscess.

\section{Case Report}

A 16 years old girl was admitted in Dhaka Medical College Hospital with the complaints of pain in neck for 5 months, fever for 5 months and weakness in all four limbs \& dysphagia for the last 3 months.Neck pain was associated with gradual stiffness. Pain was intermittent, but its frequency and duration had gradually increased. Fever was low grade, irregular, with evening rise and relieved by sweating with medication. Weakness in all 4 limbs was gradual in onset and progressive in nature associated with decreased sensation of all sensory modality in four limbs. She also complained of dysphagia and breathlessness over the few days during hospital stay. Dysphagia was more for solid food than liquid. Her bowel and bladder habit was normal.

On examination, her pulse rate was76 beats/min, BP-110/ $70 \mathrm{mmHg}$, temparature- $100^{\circ} \mathrm{F}$ on admission. Nervous system examination revealed, higher psychic function-normal, functions of all 12 cranial nerves were intact. Motor Functionbulk of muscle of upper limb-wasting of the small muscle of hand with clawing deformity of fingers of both hands. In

1. Assistant Professor, Department of Medicine, Dhaka Medical College

2. Honorary Medical Officer, Department of Medicine, Dhaka Medical College Hospital

3. Registrar, Department of Medicine, Dhaka Medical College

4. Associate Professor, Department of Medicine, Dhaka Medical College

5. Professor, Department of Medicine, Shaheed Suhrawardy Medical College

Correspondence: Dr. Md. Robed Amin, Assistant Professor, Department of Medicine, Dhaka Medical College. E-mail: robedamin@yahoo.com 
lower limb-reduced symmetrically in both the lower limb. Tone of muscle-increased in all the four limbs. Power of muscle-2/5 in all the four limbs. Jerks exaggerated in all four limbs. Planter extensor bilaterally and clonus present. Sensation is reduced in all four limbs but no definite level. Other systems were unremarkable.

On investigation, Hb-12.6g/dl, ESR-50 mm $1^{\text {st }}$ hour, total count $-65000 / \mathrm{mm}^{3}$, neutrophils-58\%, lymphocyte-36\%. Total platelet count-290000/ $\mathrm{mm}^{3}$, X-Ray of neck (both view) normal (Figure 1). Chest X-ray was normal. MRI of dorsal spine shows retropharyngeal abscess with epidural extension resulting in corresponding spinal cord compression and compressive myleopathy (Figure 2). Consultation with an ENT specialist was done and exploratoion and drainage was undertaken. A large pocket of pus was present behind the stemocleidomastoid muscle medial to the internal jugular vein. The pus was drained and sent for microbiologic examination. On an acid-fast smear, Mycobacterium tuberculosis bacilli were identified. Biopsy of tissue from posterior pharyngeal wall showed granulomatous inflammation with caseous necrosis consistent with TB. A diagnosis of Pott's disease was established, and the patient was started on antituberculous therapy. She improved rapidly over the next few days. Her neck stiffness decreased and she was able to eat comfortably. But her quadriplegia had poor improvement initially. At second week she started to show improvement with gradual movement of limbs and regaining of sensation. She was discharged with advice of anti TB drug for one year duration with steroid coverage.

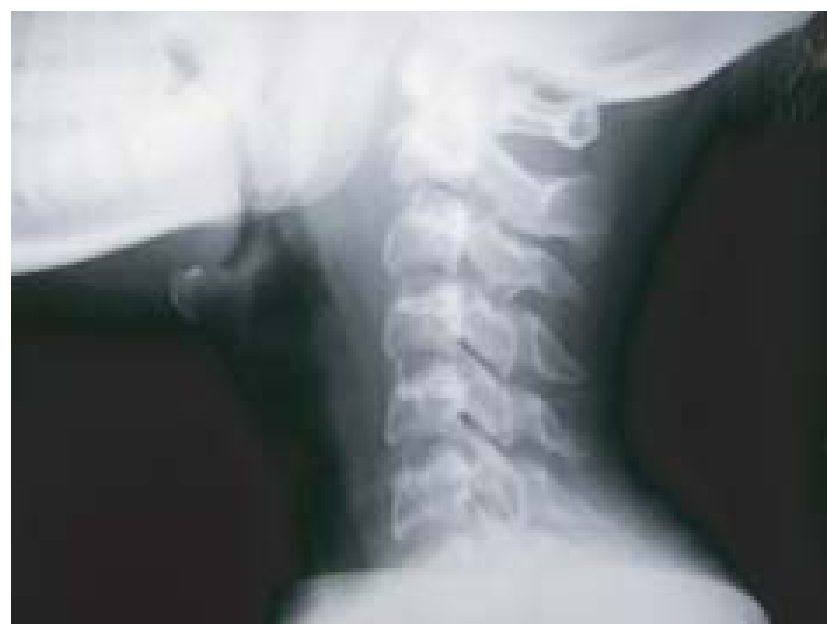

Fig.-1: Normal finding on X-ray cervical spine lateral view

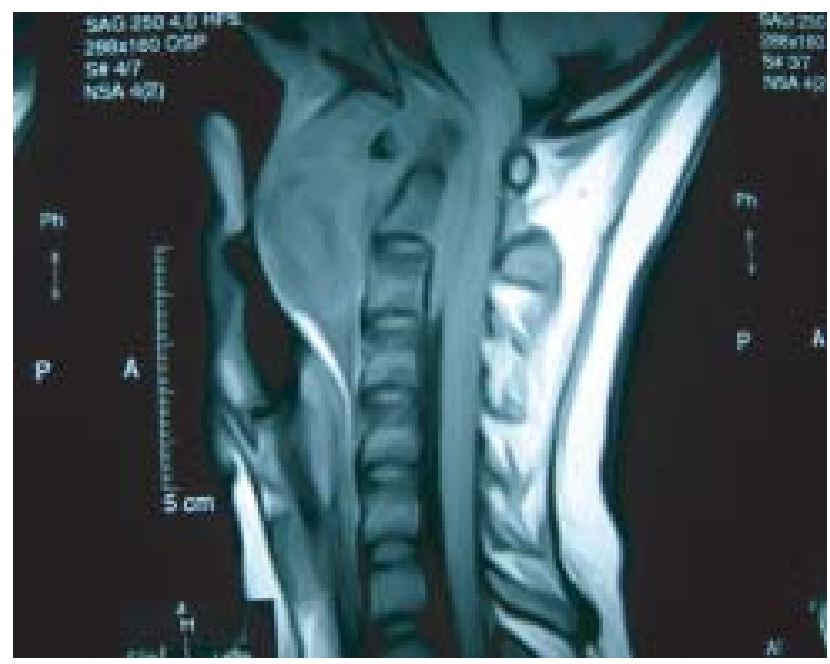

Fig.-2: MRI of cervical spine showing retropharyngeal abscess compressing the spinal cord.

\section{Discussion}

Retropharyngeal abscess (RPA) is of two types - acute \& chronic. ${ }^{3}$ Acute RPA usually occurs in children below 7 years of age because after 7 years retropharyngeal lymph nodes obliterate. Chronic RPA usually occurs in adult \& the cause almost always is tuberculosis. RPA complicated by suppuration in the central nervous system, intra- or extraaxial, is rare. ${ }^{3}$ Retropharyngeal tuberculous abscess is a rare presentation of tuberculosis, even in a patient with extensive pulmonary tuberculosis. It has been reported that $1 \%$ of all patients hospitalized with tuberculosis have skeletal tuberculosis, ${ }^{4}$ with only $7 \%$ of these having involvement of the cervical spine. ${ }^{5}$ Infection in Pott's disease originates in the pelvic organs and disseminates hematogenously via Batson's plexus to involve more superior areas of the spine in a watershed fashion. ${ }^{6}$ This explains why only the most anterior portion of the spine is involved and why Pott's disease is rare in the cervical area. Acute transverse myelopathy complicating a retropharyngeal abscess may be more frequent than epidural spinal abscess and usually affects the thoracic cord. Therefore, the occurrence of acute high cervical transverse myelopathy is rarely encountered. As the abscess expands, it may bulge anteriorly into the airway and cause respiratory obstruction, or it may compress the spinal cord and lead to weakness of the extremities and quadriplegia.

Clinical suspicion for Pott's disease should be high for any patient who presents with a destructive lesion of the spine. Radiographically, the most common finding is an osteolytic lesion with widening of the retropharyngeal soft-tissue space. ${ }^{7}$ Treatment includes incision and drainage of the abscess under antibiotic and antituberculous treatment cover. 
Early diagnosis \& treatment is vital to prevent the formation or progression of neurological deficit. The need for neuroradiologic diagnostic evaluation is emphasized in order to rule out a surgically treatable lesion.

\section{Conflict of interest: None}

\section{References}

1. Neal SL, Kearns M J, Seelig JM, et al. Manifestations of Pott's disease in the head and neck. Laryngoscope 1986;96: 494-6.

2. Todd J Berger. Retropharyngeal abscess. Available at: www.eMedicine.com.
3. De SK. Fundamental's of ear, nose, throat \& head-neck surgery, $7^{\text {th }}$ edition.

4. Melchior Diaz MA, Doningo Carrasco C, Monge Jogra R, et al. Tuberculous retropharyngeal abscess in an HIV patient: Report of a case. Acta Otorhinolaryngol Esp 1993;44:467.

5. Morton W, Dodge HJ. The present status of skeletal tuberculosis. A statement of the Subcommittee on Surgery and the Committee on Therapy. Am Rev Respir Dis 1963;88:272.

6. Fang D, Leong JC, Fang HS. Tuberculosis of the upper cervical spine. J Bone Joint Surg 1983;65(B):47-50.

7. Agarwal Salil. Tubercular retropharyngeal abscess. Ear Nose and Throat Journal 2007;1: 43-44. 